JIIA, VOLUME 8 No. 2, MEI 2020

\title{
EFISIENSI PRODUKSI USAHATANI SAYURAN (CABAI, SAWI DAN KUBIS) DI KOTA PAGAR ALAM PROVINSI SUMATERA SELATAN
}

\author{
(Production Efficiency of Vegetable (Chili, Mustard and Cabbage) Farming \\ in Pagar Alam City of South Sumatera)
}

Olpa Fuji Lestari, Ali Ibrahim Hasyim, Suriaty Situmorang

Jurusan Agribisnis, Fakultas Pertanian, Universitas Lampung, J1. Prof. Dr. Soemantri Brodjonegoro No. 1 Bandar Lampung 35141, e-mail: suriaty.situmorang@fp.unila.ac.id

\begin{abstract}
This research aims to analyze the factors that affect production of vegetable (chili,mustard and cabbage)farming and the technical efficiency. The research was conducted in North Dempo and South Pagar Alam Subdistrict of Pagar Alam. Farmer respondents were chosen by using simple random sampling. Data were collected in May-Juny 2018 and analyzed using Cobb-Douglas production functionnamely frontier production function. The results showed that factors affecting the production of chili farming are area lands, seeds and nitrogen fertilizer. Factors affecting the production of mustard farming are landsize, seeds and potassium fertilizer, and pesticide. Factors affecting the production of cabbage farming are area landslandsizeand manure. Vegetable farming (chili, mustard and cabbage) is on an increasing return to scale $(E p>1)$ or in irrational area so that it does not meet the requirement for economic efficiency. Chili and mustard farming are technically efficient with an efficiency level greater than 70,00\%. The level of technical efficiency of chili farming is $86,99 \%$ and mustard farming is $80,08 \%$. Cabbage farming is not technically efficient because the efficiency level is below 70,00\%, that is $68,72 \%$.
\end{abstract}

Key words: efficiency, farming, vegetable

\section{PENDAHULUAN}

Salah satu subsektor yang dapat dijadikan sumber pertumbuhan ekonomi di Indonesia adalah subsektor tanaman hortikultura. Tanaman hortikultura yang banyak diusahakan di Indonesia adalah tanaman sayuran. Sayuran merupakan jenis komoditas yang berperan dalam pemenuhan kebutuhan pendapatan keluarga petani, karena tanaman sayuran berumur relatif pendek sehingga dapat cepat menghasilkan, serta dapat diusahakan dengan teknologi sederhana, dan hasil produksinya dapat cepat terserap pasar. Itulah sebabnya petani menjatuhkan pilihan mengusahakan sayuran sebagai strategi untuk dapat bertahan hidup (Edy 2010).

Kota Pagar Alam merupakan sentra produksi sayuran di Provinsi Sumatera Selatan. Tanaman sayuran yang memiliki produksi paling tinggi di Kota Pagar Alam adalah cabai, kubis dan sawi dengan produksi masing-masing sebesar $44,13 \%$, $26,85 \%$ dan 20,48\%dari keseluruhan produksi sayuran di Kota Pagar Alam (Badan Pusat Statistik Kota Pagar Alam 2018).

Tabel 1 menunjukkan bahwa pada tahun 20162017 tanaman cabai dan kubis mengalami penurunan luas lahan dan produksi. Produksi tanaman sayuran (cabai, sawi dan kubis) dipengaruhi oleh penggunaan faktor-faktor produksi dalam kegiatan usahatani. Penggunaan faktor-faktor produksi secara optimal dapat meningkatkan produksi. Faktor-faktor produksi antara lain benih, pupuk, lahan, pestisida dan tenaga kerja, sedangkan faktor-faktor di luar produksi antara lain fasilitas kredit, lembaga penunjang pertanian, sarana dan prasarana serta harga yang sedang berlaku. Penggunaan faktorfaktor produksi yang tidak efisien dapat menyebabkan penurunan produksi usahatani.

Tabel 1. Sebaran luas panen dan produksi tanaman sayuran dominan di Kota Pagar Alam, tahun 2016-2017

\begin{tabular}{lcccc}
\hline \multirow{2}{*}{ Komoditas } & \multicolumn{2}{c}{$\begin{array}{c}\text { Luas panen } \\
\text { (ha) }\end{array}$} & \multicolumn{2}{c}{$\begin{array}{c}\text { Produksi } \\
\text { (ton) }\end{array}$} \\
\cline { 2 - 5 } & 2016 & 2017 & 2016 & 2017 \\
\hline Cabai & 311 & 401 & 26.006 & 41.280 \\
Sawi & 316 & 271 & 19.965 & 19.161 \\
Kubis & 390 & 392 & 22.635 & 25.119 \\
\hline Sumber: Badan Pusat Statistik Kota Pagar Alam (2018)
\end{tabular}

Tujuan utama dari usahatani adalah untuk memperoleh pendapatan yang tinggi dengan menggunakan faktor-faktor produksi yang efisien. 
Berdasarkan uraian sebelumnya, maka tujuan penelitian ini adalah untuk menganalisis faktorfaktor yang mempengaruhi usahatani sayuran (cabai, sawi dan kubis) dan tingkat efisiensi produksi usahatani sayuran (cabai, sawi dan kubis) di Kota Pagar Alam Provinsi Sumatera Selatan.

\section{METODE PENELITIAN}

Penelitian ini dilakukan di Kota Pagar Alam Provinsi Sumatera Selatan, yaitu di Kecamatan Dempo Utara dan Kecamatan Pagar Alam Selatan, Kota Pagar Alam. Pemilihan lokasi penelitian dilakukan secara sengaja (purposive) dengan pertimbangan bahwa Kecamatan Dempo Utara dan Kecamatan Pagar Alam Selatan merupakan sentra produksi sayuran di Kota Pagar Alam.

Pengambilan sampel pada penelitian dilakukan secara acak sederhana (simple random sampling). Sebelum dilakukan penelitian, terlebih dahulu dilakukan pra-survey untuk mengetahui keadaan umum populasi petani sayuran di lokasi penelitian. Populasi petani sayuran yang ada di Kecamatan Dempo Utara adalah 184 petani, yang terdiri dari 72 petani kubis, 61 petani sawi dan 51 petani cabai (Balai Penyuluhan Pertanian Kecamatan Dempo Utara 2017) dan di Kecamatan Pagar Alam Selatan adalah 110 petani, yang terdiri dari 44 petani kubis, 36 petani sawi dan 30 petani cabai (Balai Penyuluhan Pertanian Pagar Alam Selatan 2017). Penentuan ukuran sampel yang diambil merujuk pada teori Sugiarto, Sunaryanto, dan Oestomo (2003), yaitu :

$$
\mathrm{n}=\frac{\mathrm{NZ}^{2} \mathrm{~S}^{2}}{\mathrm{Nd}^{2}+\mathrm{Z}^{2} \mathrm{~S}^{2}}
$$

$$
\begin{aligned}
& \text { Keterangan : } \\
& \mathrm{n} \quad=\text { Jumlah sampel } \\
& \mathrm{N}=\text { Populasi } \\
& \mathrm{Z}=\text { Z-score dari unit populasi }(95 \%=1,96) \\
& \mathrm{S}^{2}=\text { Simpangan baku }(5 \%=0,05) \\
& \mathrm{d} \quad=\text { Standard error }(5 \%=0,05)
\end{aligned}
$$

Berdasarkan perhitungan yang dilakukan diperoleh petani sampel di Kecamatan Dempo Utara, yaitu sebanyak 37 petani kubis, 34 petani sawi dan 31 petani cabai. Petani sampel di Kecamatan Pagar Alam Selatan, yaitu 28 petani kubis, 25 petani sawi, dan 22 petani cabai. Namun, pada penelitian ini sampel yang digunakan untuk masing-masing jenis sayuran di Kecamatan Dempo Utara adalah 18 sampel dan untuk di Kecamatan Pagar Alam Selatan adalah 15 sampel untuk masing-masing jenis sayuran. Hal ini dilakukan karena sampel tersebut sudah dapat mewakili jumlah populasi di daerah penelitian. Petani sampel yang digunakan dalam penelitian ini merupakan petani sayuran monokultur, yaitu petani yang menanam atau membudidayakan satu jenis sayuran pada satu areal. Pengumpulan data penelitian dilaksanakan pada bulan Mei dan Juni 2018.

Data yang digunakan dalam penelitian ini adalah data primer dan data sekunder. Data primer diperoleh melalui wawancara dan pengamatan langsung di lapang dan data sekunder diperoleh dari lembaga atau instansi terkait, jurnal, skripsi, publikasi, dan pustaka lainnya yang terkait dan relevan dengan penelitian ini.

Metode analisis data yang digunakan adalah metode analisis deskriptif kualitatif dan kuantitatif. Analisis kualitatif dilakukan untuk mengetahui keragaan usahatani sayuran di Kota Pagar Alam. Analisis kuantitatif dilakukan untuk mengidentifikasi faktor-faktor yang mempengaruhi produksi dan tingkat efisiensi produksi usahatani sayuran di Kota Pagar Alam.

Menurut Soekartawi (2003), fungsi produksi CobbDouglas merupakan suatu fungsi atau persamaan yang melibatkan dua atau lebih variabel, variabel yang satu disebut dengan variabel $(\mathrm{Y})$ atau yang dijelaskan dan variabel lain disebut dengan variabel (X) atau yang menjelaskan. Variabel yang dijelaskan biasanya berupa output dan variabel yang menjelaskan biasanya berupa input. Secara matematis, persamaan fungsi produksi CobbDouglas dapat ditulis sebagai :

$\mathrm{Y}=\mathrm{boX} 1^{\mathrm{b} 1} \cdot \mathrm{X} 2^{\mathrm{b} 2} \cdot \mathrm{X} 3^{\mathrm{b} 3} \cdot \mathrm{X} 4^{\mathrm{b} 4} \cdot \mathrm{X} 5^{\mathrm{b} 5} \ldots \mathrm{Xb^{8 }} \mathrm{be}^{\mathrm{u}}$.

Persamaan tersebut diubah menjadi bentuk linierdengan cara melogaritmakan persamaan tersebut (Soekartawi 2003) yaitu:

$\mathrm{LnY}=\mathrm{Lnb} 0+\mathrm{b} 1 \operatorname{Ln} \mathrm{X} 1+\mathrm{b} 2 \operatorname{Ln} \mathrm{X} 2+\ldots+\mathrm{b} 8 \mathrm{LnX} 8$

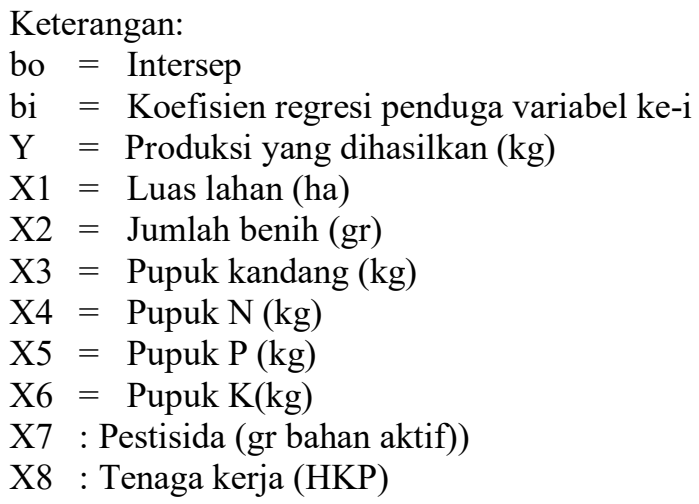


Persamaan fungsi produksi Cobb-Douglas dilakukan uji asumsi klasik yang bertujuan untuk menguji hasil perhitungan, agar tidak menghasilkan persamaan yang bias. Uji asumsi klasik yang digunakan adalah uji multikoliniearitas danheteroskedastisitas. Jika nilai VIF $>10$, maka terjadi korelasi atau hubungan bebas antar variabel. Gejala heteroskedastisitas dapat diketahui dengan melakukan Uji White. Jika hasil uji white menunjukan nilai Obs $\mathrm{R}^{2}<0,05$ maka terdapat gejala heterokedastisitas (Gujarati 2003).

Analisis efisiensi ekonomi terjadi apabila syarat keharusan terpenuhi, yaitu proses produksi harus berada pada tahap kedua yaitu pada waktu $0<\mathrm{Ep} \leq 1$ yang menunjukkan efisiensi teknis dan syarat kecukupan, yaitu pada kondisi keuntungan maksimum tercapai, dengan syarat nilai produk marginal sama dengan biaya korbanan marginal (Soekartawi 2003).

Analisis efisiensi teknis dapat dianalisis dengan menggunakan fungsi produksi frontier. Fungsi produksi frontier merupakan fungsi produksi yang dipakai untuk mengukur bagaimana fungsi produksi sebenarnya terhadap posisi frontiernya. Analisis efisiensi teknis diperoleh dengan cara membandingkan antara produksi aktual yang dihasilkan petani dengan produksi potensial atau produksi frontiernya. Pendugaan fungsi produksi frontier dilakukan dengan linear programming sebagai (Soekartawi 1994):

$\begin{array}{ll}\text { Minimalkan } & : \mathrm{a}_{0}+\sum_{\mathrm{j}} \mathrm{a}_{\mathrm{j}} \mathrm{x}_{\mathrm{j}} \\ \text { Dengan syarat } & : \mathrm{a}_{0}+\Sigma_{\mathrm{j}} \mathrm{a}_{\mathrm{j}} \mathrm{x}_{\mathrm{j}} \geq \mathrm{Yi} \\ & \mathrm{a}_{0}+\Sigma_{\mathrm{j}} \mathrm{a}_{\mathrm{j}} \mathrm{x}_{\mathrm{j}} \geq \mathrm{Yn}\end{array}$

Seluruh variabel ditransformasikan ke dalam bentuk logaritma. Output frontier diperoleh dengan cara memasukkan penggunaan inputinputkedalam fungsi produksi frontier :

$\mathrm{a}_{0}+\sum_{i=1}^{n} a_{\mathrm{i}} \mathrm{x}_{\mathrm{i}} \geq \mathrm{Yi}$

Fungsi frontier diperoleh dengan cara memasukkan penggunaan input-input ke dalam fungsi produksi frontier):

$$
\text { Yf } \quad=\mathrm{a}_{0}+\sum_{i=1}^{n} a_{\mathrm{i}} \mathrm{x}_{\mathrm{ij}}+\text { ei. }
$$

Keterangan :

Yf : Produksi potensial/frontier

$\mathrm{a}_{0}:$ Konstanta

ai : Elastisitas untuk output ke-i $(\mathrm{i}=1,2 . . \mathrm{n})$

xij : Kuantitas penggunaan input ke-j untuk usahatani ke-i $(\mathrm{j}=1,2,3 . .7)$ ei : Kesalahan-kesalahan (error)

Efisiensi teknis masing-masing petani dihitung dengan rumus :

$\mathrm{ET}=\frac{\mathrm{Yi}}{\mathrm{Yf}} \times 100 \%$

Keterangan :

ET : Tingkat efisiensi teknis (produksi)

Yi : Produksi aktual ke-i (i=1,2..n)

Yf : Produksi potensial/frontier ke-i $(1,2 \ldots \mathrm{n})$

Nilai indeks efisiensi hasil analisis dapat dikategorikan efisien dalam menggunakan input produksi apabila nilainya mendekati satu. Efisiensi teknis untuk seorang petani berkisar antara nol dan satu $(0 \leq \mathrm{ET} \leq 1)$, dimana 1 menunjukkan suatu usahatani sepenuhnya efisien secara teknis. Kategori yang digunakan dalam penelitian adalah cukup efisien jika bernilai $\geq 0,70$ dan dikategorikan belum efisien jika bernilai $<0,70$ (Coellidan Battese 1998).

Return to scale atau skala usaha suatu usahatani perlu diketahui untuk melihat apakah suatu kegiatan usahatani mengikuti kaidah increasing, constant dan decreasing. Skala usahatani dapat diketahui dengan menjumlahkan koefisien regresi yang signifikan terhadap produksi.

\section{HASIL DAN PEMBAHASAN}

\section{Karakteristik Responden}

Umur responden pada penelitian ini berkisar25 sampai dengan 68 tahun dan masuk kelompok usia produktif. Tingkat pendidikan responden tergolong rendah, yaitu sebesar $35,36 \%$ tamat SD dan sebesar $32,32 \%$ tamat SMP. Dominan (71,72\%) petani sayuran memiliki tanggungan 3-4 orang dan sebesar $66,66 \%$ petani di daerah penelitian memilki pengalaman berusatani selama 5-16 tahun. Rata-rata luas lahan yang dimiliki petanicabai adalah 0,86 ha, petani sawi 0,91 ha dan petani kubis 0,83 ha, yang terdiri dari lahan milik sendiri sebesar $40,40 \%$, sakap sebesar $42,42 \%$ dan sewa sebesar $17,17 \%$. Sebanyak $15,15 \%$ petani sayuran di Kota Pagar Alam memiliki pekerjaan lain (sampingan), seperti: berdagang, tukang bangunan, tukang ojek, dan supir. Selain itu, sebesar $94,95 \%$ petani sayuran juga melakukan kegiatan usahatani lain di luar usahatani utama, seperti: usahatani kopi, jeruk dan sayuran lainnya. 


\section{Keragaan Usahatani}

Sarana produksi usahatani sayuran (cabai, sawi dan kubis) di Kota Pagar Alam diperoleh dari kios-kios saprotan yang berada di sekitar daerah penelitian. Benih merupakan sarana produksi utama dalam kegiatan usahatani. Benih cabai yang digunakan oleh petani adalah varietas Samido, Balado, Taro dan Belinda, dengan rata-rata penggunaan sebesar 84,39 gr untuk rata-rata luas lahan cabai sebesar 0,86 ha. Selanjutnya untuk tanaman sawi, benih yang digunakan adalah varietas Alvin, Dakota, Leony dan King dengan rata-rata penggunaan sebesar 110,91 gr untuk rata-rata luas lahan 0,91 ha. Tanaman kubis menggunakan benih dengan varietas Grand 11 dan Talenta dengan rata-rata penggunaan sebesar 148,03 gr untuk rata-rata luas lahan sebesar 0,83 ha.

Penggunaan pupuk bertujuan untuk memacu pertumbuhan tanaman dan membantu menyediakan unsur hara yang kurang dalam tanah. Pemupukan juga membantu mencegah kehilangan pupuk N,P,K oleh penguapan (Nahriyanti 2008). Rata-rata penggunaan pupuk per hektar untuk tanaman sayuran (cabai, sawi dan kubis) di Kota Pagar Alam dapat dilihat pada Tabel 2.

Penggunaan tenaga kerja yang paling banyak digunakan dalam kegiatan usahatani sayuran (cabai, sawi dan kubis) di Kota Pagar Alam terbanyak adalah tenaga kerja dalam keluarga. Tenaga kerja dibutuhkan untuk mengelola usahatani seperti pengolahan tanah, penyemaian benih, penanaman, penyiangan, pemupukan, penyemprotan, pemanenan dan pengangkutan hasil panen.Pengukuran upah tenaga kerja dilakukan berdasarkan hari kerja pria (HKP) dengan upah tenaga kerja sebesar Rp 50.000/hari.

Tabel 2. Rata-rata penggunaan pupuk oleh petani sayuran (cabai, sawi dan kubis) di Kota Pagar Alam, 2018

\begin{tabular}{lrrr}
\hline \multicolumn{1}{c}{ Jenis pupuk } & \multicolumn{3}{c}{ Jumlah $(\mathrm{kg})$} \\
\cline { 2 - 4 } & \multicolumn{1}{c}{ Cabai } & \multicolumn{1}{c}{ Sawi } & \multicolumn{1}{c}{ Kubis } \\
\hline Pupuk Kandang & $10.377,03$ & $4.811,85$ & $6.681,27$ \\
Pupuk NPK & 185,87 & 12,49 & 12,12 \\
Pupuk Phonska & 81,04 & 149,02 & 193,50 \\
Pupuk Za & 29,95 & 53,28 & 50,20 \\
Pupuk KCL & 31,71 & 13,32 & 5,48 \\
Pupuk TSP & 60,78 & 14,99 & 26,47 \\
Pupuk Urea & 19,38 & 14,99 & 43,38 \\
\hline Sumber: Data Primer (diolah), 2018 & &
\end{tabular}

Total HKP untuk usahatani cabai adalah $129,81 /$ musim tanam, usahatani sawi adalah $42,22 /$ musim tanam dan untuk usahatani kubis adalah 65,79/musim tanam.

Pestisida dalam usahatani digunakan untuk memberantas hama dan penyakit yang menyerang tanaman. Pestisida yang digunakan oleh petani sayuran (cabai, sawi dan kubis) tergantung kepada serangan hama dan penyakit tanaman (HPT) yang dihadapi oleh petani. Serangan hama, seperti: ulat, lalat buah, kutu, tungau dan serangga diatasi dengan penggunaan insektisida seperti Instop,Winder, Biokron, Abenz, dan Starban. Serangan penyakit, seperti jamur, bercak daun dan busuk akar akan diatasi dengan penggunaan fungisida seperti Antracol, Victory, Tridex dan Cadilx. Pengendalian hama dan penyakit pada tanaman dilakukan dengan cara penyemprotan. Penyemprotan pestisida biasanya dilakukan sekitar 2 sampai 4 kali untuk tanaman sawi dan kubis. Tanaman cabai penyemprotan dilakukan lebih dari 5 kali tergantung dengan kondisi tanaman.

\section{Pendapatan Usahatani Sayuran (Cabai, Sawi dan Kubis) di Kota Pagar Alam}

Tabel 3 menunjukan bahwa usahatani sayuran (cabai, sawi dan kubis) di Kota Pagar Alam menguntungkan dan layak untuk diusahakan, karena penerimaan yang diperoleh lebih besar dibandingan dengan total biaya yang dikeluarkan serta nilai $\mathrm{R} / \mathrm{C}$ tunai dan $\mathrm{R} / \mathrm{C}$ total yang diperoleh lebih besar dari 1.

Tabel 3. Rata-rata penerimaan, biaya, pendapatan dan R/C usahatani sayuran (cabai, sawi dan kubis) di Kota Pagar Alam, 2018

\begin{tabular}{lrrr}
\hline \multirow{2}{*}{ Uraian (Rp) } & \multicolumn{3}{c}{ Jenis Tanaman } \\
\cline { 2 - 4 } & \multicolumn{1}{c}{ Cabai } & \multicolumn{1}{c}{ Sawi } & \multicolumn{1}{c}{ Kubis } \\
\hline $\begin{array}{l}\text { Penerimaan } \\
\text { Biaya }\end{array}$ & 84.974 .668 & 16.704 .958 & 25.906 .257 \\
Biaya tunai & 20.220 .316 & 4.801 .966 & 5.629 .609 \\
$\begin{array}{l}\text { Biaya } \\
\text { diperhtungkan }\end{array}$ & 11.922 .098 & 6.529 .440 & 7.674 .054 \\
Biaya total & 32.142 .414 & 11.331 .406 & 13.303 .664 \\
$\begin{array}{l}\text { Pendapatan } \\
\text { Pendapatan }\end{array}$ & & & \\
tunai & 64.754 .352 & 11.902 .992 & 20.276 .647 \\
Pendapatan & & & \\
total & 52.832 .254 & 5.373 .551 & 12.602 .59 \\
R/C tunai & 4,20 & 3,48 & 4,60 \\
R/C total & 2,64 & 1,47 & 1,95 \\
\hline Sumber: Data Primer (diolah), 2018 & & \\
\multicolumn{3}{l}{}
\end{tabular}


Faktor-Faktor yang Memengaruhi Produksi Usahatani Sayuran (Cabai, Sawi dan Kubis) di Kota Pagar Alam

\section{Usahatani Cabai}

Hasil analisis faktor-faktor yang mempengaruhi produksi usahatani cabai di Kota Pagar Alam disajikan pada Tabel 4. Nilai Adjusted $R$ Square usahatani cabai diperoleh sebesar 0,748, yang berarti bahwa sebesar $74,80 \%$ variasi produksi cabai di Kota Pagar Alam dapat dijelaskan oleh variabel luas lahan (X1), benih (X2), pupuk kandang (X3), pupuk N (X4), pupuk P (X5), pupuk $\mathrm{K}$ (X6), pestisida (X7) dan tenaga kerja (X8) sedangkan sisanya sebesar $25,20 \%$ dijelaskan oleh variabel lain yang tidak termasuk di dalam model. Hasil uji multikolinearitas dan heteroskedastisitas menunjukkan bahwa model yang digunakan dalam $1 \%$ akan meningkatan produksi cabai sebesar $0,26 \%$. Penelitian ini tidak mengalami multikolinearitas dan heteroskedastisitas. Fstatistik menunjukkan bahwa variabel luas lahan (X1), benih (X2), pupuk kandang (X3), pupuk N (X4), pupuk P (X5), pupukK (X6), pestisida (X7) dan tenaga kerja (X8).

Persamaan fungsi produksi Cobb-Douglass usahatani cabai di Kota Pagar Alam secara bersama-sama berpengaruh nyata terhadap produksi cabai dengan tingkat kepercayaan $99,00 \%$.

Tabel 4. Hasil analisis regresi pendugaan model fungsi produksi cabai di Kota Pagar Alam, 2018

\begin{tabular}{|c|c|c|c|c|}
\hline Model & Koefisien & T-Statistic & Sig. & VIF \\
\hline Konstanta & 8,007 & 4,570 & 0,000 & \\
\hline LnX1 (Luas Lahan) & $0,900^{* * *}$ & 4,499 & 0,000 & 2,664 \\
\hline LnX2 (Benih) & $0,391^{*}$ & 1,737 & 0,095 & 4,574 \\
\hline LnX3 (Pupuk & 0,166 & $-0,794$ & 0,435 & 3,522 \\
\hline \multicolumn{5}{|l|}{ Kandang) } \\
\hline LnX4 (Pupuk N) & $0,255^{* *}$ & 2,117 & 0,045 & 3,443 \\
\hline LnX5 (Pupuk P) & $-0,119$ & $-1,602$ & 0,122 & 1,960 \\
\hline LnX6 (Pupuk K) & 0,046 & 0,494 & 0,626 & 1,673 \\
\hline LnX7 (Pestisida) & $-0,008$ & $-0,128$ & 0,899 & 1,328 \\
\hline LnX8 (Tenaga & $-0,022$ & $-0,117$ & 0,908 & 1,210 \\
\hline \multicolumn{5}{|l|}{ Kerja) } \\
\hline$R$-Squared & & 0,831 & & \\
\hline Adjusted R-squared & & 0,777 & & \\
\hline$F$-statistic & & 14,932 & 0,000 & \\
\hline Prob Obs*R-squared & & 0,629 & & \\
\hline \multicolumn{5}{|l|}{ Keterangan : } \\
\hline *** :Nyata pada taraf & kepercaya & $9 \%$ & & \\
\hline : Nyata pada taraf & kepercayaan & $95 \%$ & & \\
\hline : Nyata pada taraf & kepercayaa & $0 \%$ & & \\
\hline
\end{tabular}

Persamaan fungsi produksi Cobb-Douglass usahatani cabai di Kota Pagar Alam Adalah :

$$
\begin{aligned}
& \mathrm{Y}=3001,90 \mathrm{X} 1^{0,900^{* * *}} \mathrm{X} 2^{0,391^{*}} \cdot \mathrm{X} 3^{-0,166} \cdot \mathrm{X} 4^{0,255^{* *}} \text {. } \\
& \mathrm{X} 5^{-0,119} \cdot \mathrm{X}^{0,046} \cdot \mathrm{X} 7^{-0,008} \cdot \mathrm{X}^{0} \mathrm{-}^{0,022}
\end{aligned}
$$

Tabel 4 menunjukkan bahwa variabel luas lahan berpengaruh nyata terhadap produksi usahatani cabai pada tingkat kepercayaan $99 \%$, dengan nilai koefisien 0,900 yang artinya setiap penambahan penggunaan luas lahan $1 \%$ akan meningkatkan produksi cabai sebesar $0,90 \%$. Benih berpengaruh nyata terhadap produksi usahatani cabai pada tingkat kepercayaan 90\%, dengan nilai koefisien 0,391 yang artinya setiap penambahan penggunaan benih $1 \%$ akan meningkatkan produksi cabai sebesar $0,39 \%$. Pupuk $\mathrm{N}$ berpengaruh nyata terhadap produksi usahatani cabai pada tingkat kepercayaan 95\%, dengan nilai koefisien 0,255 yang artinya setiap penambahan penggunaan pupuk $\mathrm{N}$ sebesar $1 \%$ akan meningkatkan produksi cabai sebesar $0,26 \%$.

\section{Usahatani Sawi}

Nilai Adjusted $R$ Square sebesar 0,716, yang berarti bahwa sebesar $71,60 \%$ variasi produksi sawi dapat dijelaskan oleh variabel luas lahan (X1), benih (X2), pupuk kandang (X3), pupuk N (X4), pupuk P (X5), pupukK (X6), pestisida (X7) dan tenaga kerja (X8). Sisanya, sebesar $28,40 \%$ dijelaskan oleh variabel lain yang tidak termasuk di dalam model dapat dilihat pada Tabel 5.

Tabel 5. Hasil analisis regresi pendugaan model fungsi produksi sawi di Kota Pagar Alam, 2018

\begin{tabular}{lcrrc}
\hline \multicolumn{1}{c}{ Model } & Koefisien & T-Statistic & Sig. & VIF \\
\hline Konstanta & 5,957 & 6,084 & 0,000 & \\
LnX1 (Luas Lahan) & $0,320^{* *}$ & 2,652 & 0,014 & 1,572 \\
LnX2 (Benih) & $0,597^{* * *}$ & 5,873 & 0,000 & 1,584 \\
LnX3 (Pupuk & $-0,078$ & $-0,682$ & 0,502 & 1,758 \\
Kandang) & & & & \\
LnX4 (Pupuk N) & 0,091 & 0,882 & 0,387 & 1,820 \\
LnX5 (Pupuk P) & $-0,302$ & $-1,572$ & 0,129 & 5,412 \\
LnX6 (Pupuk K) & $0,345^{* *}$ & 2,240 & 0,035 & 4,912 \\
LnX7 (Pestisida) & $0,042^{*}$ & 1,851 & 0,076 & 1,642 \\
LnX8 (Tenaga & 0,052 & 0,196 & 0,846 & 2,227 \\
Kerja) & & & & \\
\hline R-Squared & & 0,787 & & \\
Adjusted $R$-squared & & 0,716 & & \\
F-statistic & & 11,074 & 0,000 & \\
Prob Obs $*$-squared & & 0,098 & & \\
\hline Keterangan: & & &
\end{tabular}

Keterangan :

*** : :Nyata pada taraf kepercayaan $99 \%$

** : : Nyata pada taraf kepercayaan $95 \%$

* : : Nyata pada taraf kepercayaan $90 \%$ 
Hasil uji multikolinearitas dan heteroskedastisitas menunjukkan bahwa model yang digunakan dalam penelitian tidak mengalami multikolinearitas dan heteroskedastisitas. F-statistic menunjukkan bahwa variabel luas lahan (X1), benih (X2), pupuk kandang (X3), pupuk N (X4), pupuk $\mathrm{P}$ (X5), pupuk $\mathrm{K}$ (X6), pestisida (X7) dan tenaga kerja (X8) secara bersama-sama nyata berpengaruh terhadap produksi sawi dengan tingkat kepercayaan $99 \%$.

Persamaan fungsi produksi Cobb-Douglass usahatani sawi di Kota Pagar Alam adalah :

$\mathrm{Y}=386,45 \mathrm{X} 1^{0,320^{* *}} \cdot \mathrm{X} 2^{0,597^{* * *}} \cdot \mathrm{X} 3^{-, 0,078} \cdot \mathrm{X} 4^{0,091}$ $\mathrm{X} 5^{-0,302} \cdot \mathrm{X} 6^{0,345^{* *}} \cdot \mathrm{X} 7^{0,042^{*}} \cdot \mathrm{X} 8^{0,052}$

Tabel 5 menunjukkan bahwa variabel luas lahan berpengaruh nyata terhadap produksi usahatani sawipada tingkat kepercayaan $95 \%$, dengan nilai koefisien 0,320 yang artinya setiap penambahan penggunaan luas lahan $1 \%$ akan meningkatkan produksi sawi sebesar $0,32 \%$. Benih berpengaruh nyata terhadap produksi usahatani sawi pada tingkat kepercayaan 99\%, dengan nilai koefisien 0,590 yang artinya setiap penambahan penggunaan benih $1 \%$ akan meningkatkan produksi sawi sebesar $0,59 \%$. Pupuk $\mathrm{K}$ berpengaruh nyata terhadap produksi usahatani sawi pada tingkat kepercayan 95\%, dengan nilai koefisien 0,345 yang artinya setiap penambahan penggunaan pupuk $\mathrm{K} 1 \%$ akan meningkatkan produksi sawi sebesar $0,35 \%$. Pestisida berpengaruh nyata terhadap produksi usahatani sawi pada tingkat kepercayaan $90 \%$, dengan nilai koefisien 0,042 yang artinya setiap penambahan penggunaan pestisida $1 \%$ akan meningkatkan produksi sawi sebesar $0,04 \%$.

\section{Usahatani Kubis}

Hasil analisis faktor-faktor yang mempengaruhi produksi usahatani kubis di Kota Pagar Alam disajikan pada Tabel 6. Nilai Adjusted $R$-Square sebesar 0,716 berarti bahwa sebesar $66,70 \%$ variasi produksi kubis dapat dijelaskan oleh variabel luas lahan (X1), benih (X2), pupuk kandang (X3), pupuk N (X4), pupuk P (X5), pupuk K (X6), pestisida (X7) dan tenaga kerja (X8). Sisanya, sebesar 33,30\% dijelaskan oleh variabel lain yang tidak termasuk di dalam model.

Hasil uji multikolinearitas dan heteroskedastisitas menunjukkan bahwa model yang digunakan dalam penelitian tidak mengalami multikolinearitas dan heteroskedastisitas.
Tabel 6. Hasil analisis regresi pendugaan model fungsi produksi kubis di Kota Pagar Alam, 2018

\begin{tabular}{lcccc}
\hline \multicolumn{1}{c}{ Model } & Koefisien & T-Statistic & \multicolumn{1}{c}{ Sig. } & VIF \\
\hline & 3,522 & 1,819 & 0,081 & \\
LnX1 (Luas lahan) & $0,484^{* *}$ & 3,027 & 0,006 & 1,758 \\
LnX2 (Benih) & 0,334 & 1,662 & 0,110 & 2,834 \\
LnX3 (Pupuk & $0,583^{*}$ & 1,981 & 0,059 & 3,316 \\
kandang) & & & & \\
LnX4 (Pupuk N) & 0,116 & 1,157 & 0,259 & 2,101 \\
LnX5 (Pupuk P) & $-0,035$ & $-0,365$ & 0,718 & 1,405 \\
LnX6 (Pupuk K) & $-0,086$ & $-0,683$ & 0,501 & 1,989 \\
LnX7 (Pestisida) & 0,013 & 0,440 & 0,664 & 1,421 \\
LnX8 (Tenaga & $-0,280$ & $-0,961$ & 0,346 & 1,846 \\
kerja) & & & & \\
R-Squared & & 0,750 & & \\
Adjusted R-squared & & 0,667 & & \\
F-statistic & & 9,015 & 0,000 & \\
Prob Obs $*$ R-squared & & 0,155 & & \\
\hline Ketengn
\end{tabular}

Keterangan :

** : Nyata pada taraf kepercayaan $95 \%$

* : Nyata pada taraf kepercayaan $90 \%$

F-statistic menunjukkan bahwa variabel luas lahan (X1), benih (X2), pupuk kandang (X3), pupuk $\mathrm{N}$ (X4), pupuk P (X5), pupuk K (X6), pestisida (X7) dan tenaga kerja (X8) secara bersama-sama nyata berpengaruh terhadap produksi kubis dengan tingkat kepercayaan 99\%.

Persamaan fungsi produksi Cobb-Douglass usahatani kubis di Kota Pagar Alam adalah:

$$
\begin{aligned}
\mathrm{Y}= & 33,85 X 1^{0,484^{* *}} \cdot \mathrm{X} 2^{0,334} \cdot \mathrm{X} 3^{0,583^{*}} \cdot \mathrm{X} 4^{0,116} . \\
& \mathrm{X} 5^{-0,035} \cdot \mathrm{X} 6^{-0,086} \cdot \mathrm{X} 7^{0,013} \cdot \mathrm{X} 8^{-0,280} \cdots \cdots \cdots \cdots \cdots
\end{aligned}
$$

Tabel 6 menunjukkan bahwa variabel luas lahan berpengaruh nyata terhadap produksi usahatani kubis pada tingkat kepercayaan $95 \%$, dengan nilai koefisien 0,484 yang artinya setiap penambahan penggunaan luas lahan $1 \%$ akan meningkatkan produksi kubis sebesar $0,48 \%$ dan pupuk kandang berpengaruh nyata terhadap produksi usahatani kubis pada tingkat kepercayaan 95\%, dengan nilai koefisien 0,583 yang artinya setiap penambahan penggunaan pupuk kandang $1 \%$ akan meningkatkan produksi kubis sebesar $0,58 \%$.

\section{Skala Ekonomi Usaha (Return to Scale) Usahatani Sayuran (Cabai, Sawi dan Kubis)}

Usahatani cabai memiliki jumlah nilai elastisitas sebesar 1,546 berarti besaran elastisitas lebih besar dari 1 dan dinyatakan berada pada skala usaha increasing return to scale. Hal ini berarti bahwa dengan menambah penggunaan semua faktor produksi cabai yang nyata berpengaruh (luas lahan, benih dan pupuk $\mathrm{N}$ ) sebesar $1 \%$, maka akan 
meningkatkan penambahan produksi cabai sebesar $1,55 \%$. Usahatani sawi juga memiliki jumlah nilai elastisitas 1,304 berarti besaran elastisitas lebih besar dari 1 dan dinyatakan berada pada skala usaha increasing return to scale. Dengan menambah penggunaan semua faktor produksi sawi yang nyata berpengaruh (luas lahan, benih, pupuk $\mathrm{K}$ dan pestisida) sebesar $1 \%$, maka akan meningkatkan penambahan produksi sawi sebesar $1,30 \%$. Demikian pula, usahatani kubis juga memiliki jumlah nilai elastisitas sebesar 1,067 berarti besaran elastisitas lebih besar dari 1 dan dinyatakan berada pada skala usaha increasing return to scale. Hal ini berarti bahwa dengan menambah penggunaan semua faktor produksi kubis yang nyata berpengaruh (luas lahan dan pupuk kandang) sebesar $1 \%$, maka akan meningkatkan produksi kubis sebesar 1,07\%.

\section{Efisiensi Teknis Usahatani Sayuran (Cabai, Sawi dan Kubis) di Kota Pagar Alam}

Tabel 7 menunjukkan tingkat efisiensi teknis usahatani sayuran (cabai, sawi dan kubis). Usahatani cabai sudah cukup efisien secara teknis, karena memiliki nilai efisiensi teknis sebesar 85,06\%. Petani cabai di Kota Pagar Alam masih memiliki kesempatan sebesar 14,94\% untuk meningkatkan produksi potensialnya. Secara individu, efisiensi teknis yang dicapai oleh masingmasing petani cukup bervariasi, sebagian besar (57,58\%) petani responden berada pada klasifikasi tingkat efisiensi teknis antara 70,00\%-99,99\%. Perbedaan tingkat efisiensi teknis petani dalam mencapai produksi batas atau frontier di lokasi penelitian disebabkan oleh keterbatasan modal yang dimiliki petani untuk mendapatkan input produksi dalam kegiatan usahatani cabai serta cara pengelolaan input produksi yang lebih baik.

Hasil pengolahan data menggunakan program excel diperoleh nilai rata-rata produksi frontier atau potensial (YF) usahatani cabai adalah $6.642,57 \mathrm{~kg} / \mathrm{ha}$, sedangkan produksi aktual (Y aktual) adalah $5.624,24 \mathrm{~kg} / \mathrm{ha}$. Usahatani sawi sudah cukup efisien secara teknis, karena memiliki nilai efisiensi teknis sebesar $80,07 \%$. Petani sawi di Kota Pagar Alam masih memiliki kesempatan sebesar $19,93 \%$ untuk meningkatkan produksi potensialnya. Secara individu, efisiensi teknis yang dicapai oleh masing-masing petani cukup bervariasi, sebagian besar $(60,61 \%)$ petani responden berada pada klasifikasi tingkat efisiensi teknis antara 70,00\%-99,99\%.
Tabel 7. Tingkat efisiensi teknis usahatani sayuran (cabai, sawi dan kubis) di Kota Pagar Alam, 2018

\begin{tabular}{crrr}
\hline Tingkat Efisiensi(\%) & \multicolumn{1}{c}{ Cabai } & \multicolumn{1}{c}{ Sawi } & \multicolumn{1}{c}{ Kubis } \\
\hline$<70,00$ & 15,15 & 21,21 & 54,55 \\
$70,00-99,99$ & 57,58 & 60,61 & 39,39 \\
100,00 & 27,27 & 18,18 & 6,06 \\
\hline Jumlah & 100,00 & 100,00 & 100,00 \\
\hline Rata-rata & 85,06 & 80,07 & 69,43 \\
\hline
\end{tabular}

Sumber: Data Primer (diolah),2018

Perbedaan tingkat efisiensi teknis petani dalam mencapai produksi batas atau frontier di lokasi penelitian disebabkan oleh keterbatasan modal yang dimiliki petani untuk mendapatkan input produksi dalam kegiatan usahatani sawi serta cara pengelolaan input produksi yang lebih baik. Hasil pengolahan data menggunakan program excel diperoleh nilai rata-rata produksi frontier atau potensial (YF) usahatani sawi adalah 8.836,83 $\mathrm{kg} / \mathrm{ha}$, sedangkan produksi aktual ( $\mathrm{Y}$ aktual) yaitu adalah $7.090,91 \mathrm{~kg} / \mathrm{ha}$.

Usahatani kubis belum efisien secara teknis, karena hanya memiliki nilai efisiensi teknis sebesar 69,43\%. Petani kubis di Kota Pagar Alam masih memiliki kesempatan sebesar $31,57 \%$ untuk meningkatkan produksi potensialnya. Secara individu, efisiensi teknis yang dicapai oleh masingmasing petani cukup bervariasi, sebagian besar $(54,55 \%)$ petani responden berada pada klasifikasi tingkat efisiensi teknis $<70,00 \%$. Perbedaan tingkat efisiensi teknis petani dalam mencapai produksi batas atau frontier di lokasi penelitian disebabkan oleh keterbatasan modal yang dimiliki petani untuk mendapatkan input produksi dalam kegiatan usahatani kubis serta cara pengelolaan input produksi yang lebih baik. Hasil pengolahan data menggunakan program excel diperoleh nilai rata-rata produksi frontier atau potensial (YF) usahatani kubis adalah $11.639,96 \mathrm{~kg} / \mathrm{ha}$, sedangkan produksi aktual (Y aktual) adalah $7.969,69 \mathrm{~kg} / \mathrm{ha}$.

Hasil penelitian ini sejalan dengan penenlitian yang dilakukan Fermadi, Prasmatiwi dan Kasymir (2015)yang menyatakan bahwa luas lahan (X1), benih (X2) dan tenaga kerja (X3) mempengaruhi produksi jagung danberada pada skala usaha daerah I (increasing return to scale). Selain itu,penelitian ini juga sejalan dengan penelitian Maryanto, Sukiyono dan Priyono (2018) yang menyatakan bahwa semua faktor produksi berpengaruh secara nyata terhadap produksi kentang, kecuali tenaga kerja dan insektisida yang tidak berpengaruh nyata dengan rata-rata tingkat efisiensi teknis petani kentang sebesar 0,813. 
Penelitian yang dilakukan Silitonga, Damayanti dan Nainggolan (2018) menyatakan bahwa faktorfaktor produksi usahatani sayuran (sawi, bayam dan kangkung) secara bersama-sama berpengaruh nyata terhadap produksi sayuran, secara parsial penggunaan faktor produksi lahan, benih dan pupuk kandang berpengaruh signifikan terhadap sawi dan kangkung.

\section{KESIMPULAN}

Faktor-faktor produksi usahatani cabai yang berpengaruh nyata di lokasi penelitian adalah luas lahan, benih dan pupuk N, faktor-faktor produksi usahatani sawi yang berpengaruh nyata adalah luas lahan, benih,pupuk $\mathrm{K}$ dan pestisida, sedangkan faktor-faktor produksi usahatani kubis yang berpengaruh nyata adalah luas lahan dan pupuk kandang. Penggunaan faktor-faktor produksi usahatani cabai dan sawi sudah cukup efisien secara teknis dengan tingkat efisiensi masing-masing sebesar $86,99 \%$ dan $80,08 \%$, sedangkan penggunaan faktor-faktor produksi usahatani kubis belum efisien secara teknis, karena tingkat efisiensi teknisnya hanya sebesar $68,72 \%$. Usahatani sayuran (cabai,sawi dan kubis) di Kota Pagar Alam berada pada daerah increasing return to scale $(\mathrm{Ep}>1)$.

\section{DAFTAR PUSTAKA}

BPS [Badan Pusat Statistik] Kota Pagar Alam. 2018. Luas Panen, Produksi dan Produktivitas Tanaman Sayuran Menurut Kecamatan di Kota Pagar Alam 2017.https://pagaralamkota.bps.go.id/publi cation/2018/08/16/kota-pagar-alamdalamangka-2018.html.[5 Mei 2018].

Balai Penyuluhan Pertanian Kecamatan Dempo Utara. 2017. Data Populasi Petani Sayuran. Kecamatan Dempo Utara Kota Pagar Alam.

Balai Penyuluhan Pertanian Kecamatan Pagar Alam Selatan. 2017. Data Populasi Petani Sayuran. Kecamatan Pagar Alam Selatan Kota Pagar Alam.
Coelli T and Battese GE. 1998. An Introduction to Efficiency and Productivity Analysis. Kluwer Academic Publishers. Boston.

Edy S. 2010. Budidaya Tanaman Sayuran. Balai Pengkajian Teknologi Jambi. Jambi.

Fermadi O, Prasmatiwi FE dan Kasymir E.2015. Analisis efisiensi produksi dan keuntungan usahatani jagung di Kabupaten Ogan Komering Ulu Timur Sumatra Selatan. JIIA,3 (4):107-113.http://jurnal/fp.unila. ac.id/index.php/JIIA/article/view/1024/92.

[6 Januari 2019].

Gujarati DN. 2003. Ekonometrika Dasar. Diterjemahkan oleh S. Zain. Erlangga. Jakarta.

Maryanto MA, Sukiyono Kdan Priyono BS.2018. Analisis efisiensi teknis dan faktor penentunya pada usahatani kentang (Solanum tuberosum L.) di Kota Pagar Alam, Provinsi Sumatera Selatan. Journal of Agribusiness and Rural Development Research, 4 (1): 18.https.//doi.org/10.18196/agr.4154. [6 Januari 2019].

Nahriyanti. 2008. Analisis efisiensi penggunaan faktor-faktor produksi pada usahatani jagung. Skripsi. Universitas Hasanudin. Makassar.

Silitonga AS, Damayanti Y, dan Nainggolan S. 2018. Analisis efisiensi ekonomi penggunaan faktor produksi beberapa jenis usahatani sayuran di Kecamatan Sungai Gelam Kabupaten Muaro Jambi. Jurnal Ilmu Sosio Ekonomi Bisnis, 20 (1): 111.https://online-journal.unja.ac.id/jseb/arti cle/view/5034/3430. [6 Januari 2019].

Soekartawi. 1994. Teori Ekonomi Produksi dengan Pokok Bahasan Analisis Fungsi CobbDouglass. Rajawali Pers. Jakarta.

Soekartawi. 2003. Prinsip Dasar Ekonomi Pertanian: Teori dan Aplikasi. Raja Grafindo Persada. Jakarta.

Sugiarto D, Sunaryanto S dan Oetomo DS. 2003. Teknik Sampling. Gramedia Pustaka Utama. Jakarta. 